\title{
CRABNEBULA DIGITAL SUITE, AN ALGORITHM OF SURVEY AND 3D MODELLING FOR THE PRESERVATION AND MANAGEMENT OF URBAN HERITAGE
}

\author{
Giacinto Taibi ${ }^{\mathrm{a}}$, Rita Valenti ${ }^{\mathrm{a}}$, Mariangela Liuzzo ${ }^{\mathrm{b}}$, Massimo D’Aiello ${ }^{\mathrm{a}}$ \\ ${ }^{a}$ Special Educational Structure of Architecture of Siracusa, University of Catania, Italy \\ - giacinto.taibi@gmail.com, ritam.valenti@gmail.com, max.daiello@gmail.com \\ ${ }^{\mathrm{b}}$ Faculty of Engineering and Architecture, KORE University of Enna, Italy - mariangela.liuzzo@ unikore.it
}

KEY WORDS: Urban Survey, Architectonic Survey, 3D Modelling, Digital Suite, Web Application, Qr Code, Augmented Reality

\begin{abstract}
:
Safeguarding the cultural patrimony represents one of the objectives and one of the most important challenges of our time, because only this can ensure the conservation of the documented historical memory of our civilizations. The first level of safeguarding is knowledge, that means, in some ways and in any case, to document. Indeed, documentation constitutes an indispensable support for the protection of the cultural patrimony. In recent times, the evolution of concepts and the progress of technologies have meant that the cultural and scientific debate should evolve in the examination of which type of documentation is the most suitable.

Today, the need to observe city sites by entering their meanders and penetrating their reality with the aim of being able to interpret, understand and appreciate the values of the more recondite intimacies of the places, is increasingly felt.

The methodological approach of this study tackles the issue of managing information that is highly interrelated, referring to the entire monumental unicum of Ortigia, by means of recognition of the parts, at times also fragmentary. With this responsibility, a suite of digital instruments, online and offline, called Crabnebula, has been conceived and already applied to a significant portion of Ortigia, with the aim of uniting various useful information towards a critical interpretation of the places: from the integrated environmental, urban and architectonic survey, to the three-dimensional rendered model.
\end{abstract}

\section{INTRODUCTION (G. Taibi)}

\section{A protection charter oriented towards an algorithmic system of survey and 3D modelling.}

Safeguarding the cultural patrimony equally represents one of the objectives and as well as one of the most important challenges of our time, because only this can ensure the conservation of the documented historical memory of our civilizations; this safeguarding - that we consider here from a scientific, technical and technological viewpoint - is foremost a moral, social and educational problem. Indeed, it not only presents problematic operational aspects, but programming and managerial as well as social and educational.

The first level of safeguarding is, obviously, knowledge; knowing signifies, in some way and in every case, to document. Documentation, indeed, constitutes an indispensable support for the protection of the cultural patrimony. In recent times, the evolution of concepts and technological progress has meant that the cultural and scientific debate has evolved in the examination of which type of documentation is the most suitable.

Today the need is increasingly felt to observe city sites by entering their meanders and penetrating their reality with the aim of being able to interpret, understand and appreciate the values of the more recondite intimacies of its places. (Figure 1) In many cases, the current urban configuration is the outcome of articulated stratifications and transformations which have occurred over the course of centuries, therefore the task of interpreting its complexity may happen, only and exclusively, through the meaningful and appropriate integrated reading of archival, cartographic and signic data of the physical structure. Everything previously expressed, inevitably, leads to the reflection of the future, directed towards what is to become of it.
The passionate and intense impulse, constantly directed towards the achievement of the perfecting of procedure, has already produced the initial concretization in the defining of a suitable structure with which to relate with external context.

According to a wider view point there is a great need to establish, widespread among the territories, laboratories that monitor and control the artistic production; in this way the eventual application of the Laboratory of the Representation of the Special Didactic Structure of Architecture coagulates and collects, through an osmotic process, a continuous transfer of information, indispensable for the verification of the adequacy of the morphogenetic posture with the pre-existing environment. It is necessary to reason in terms of laboratories, which if thought of as small control towers, mutually connected and interacting, represent pseudo Environmental Observatories, capable of monitoring and controlling, with a wide range of reach, the "evolving", meant as the manifestation of a mutual relationship between both parts.

The previously mentioned commitment - actively present in the desire to direct particular attention towards the posed problems, in a natural manner, woven within the environmental fabric proposes the creation of a control document.

It is non-deferrable, within a systemic logic, the ability to reason in terms of integrated activities containing a suite of digital instruments, both online and offline, which are indispensable for the Factory of Knowledge referring to the environmental survey, urban and architectonic. (Figure 2)

At this point the opportunity to take advantage of today's multimedia technologies available in commerce becomes a priority in order to promote a systematic collecting of information, that opportunely catalogued and dated, within their overlapping and relating, can allow for a global comprehension based on the discernment and recomposing of the parts. 

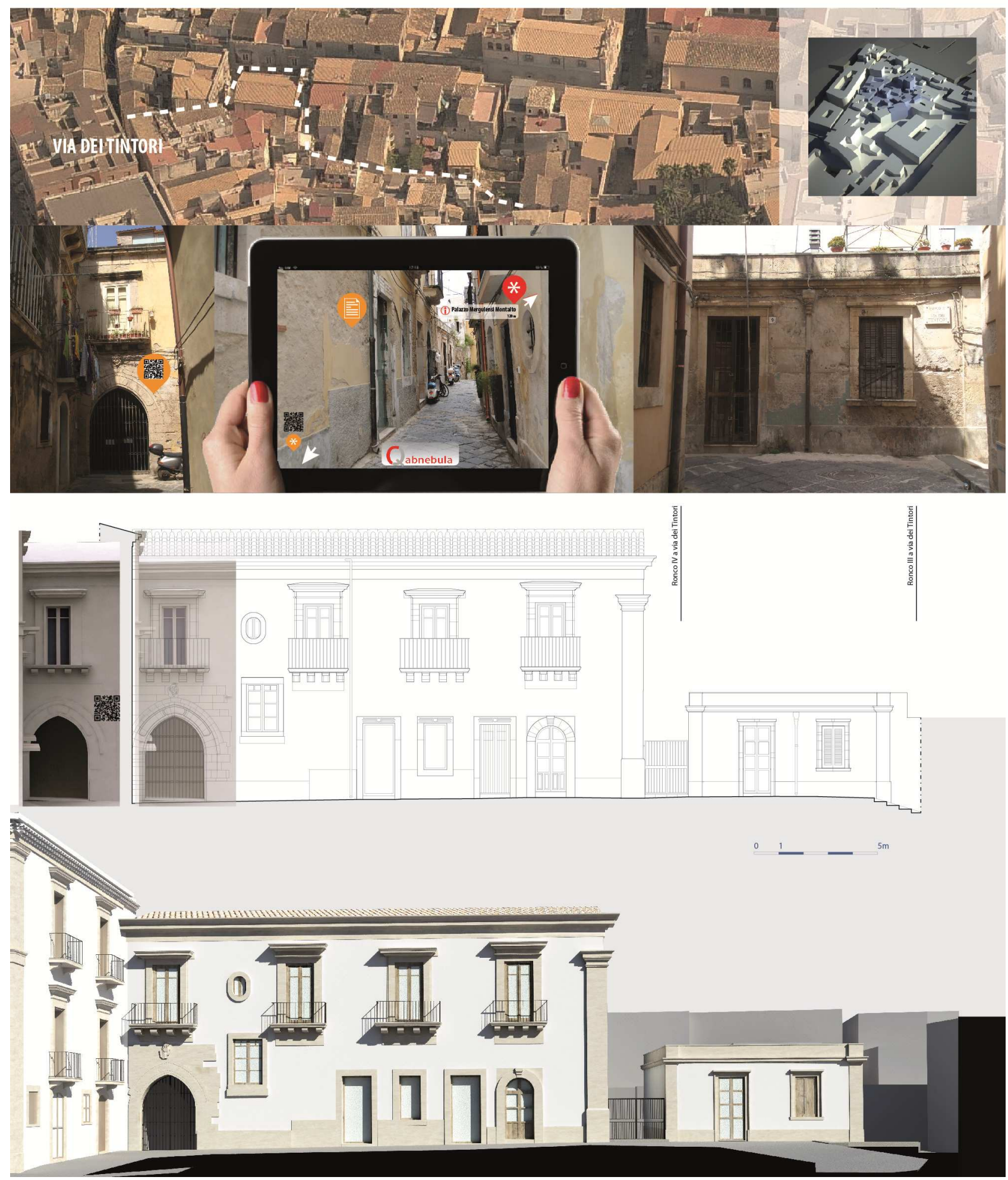

Figure 1. Examples of interaction between add ins of the "Charter of Quality" document in the process of the knowledge of buildings. 

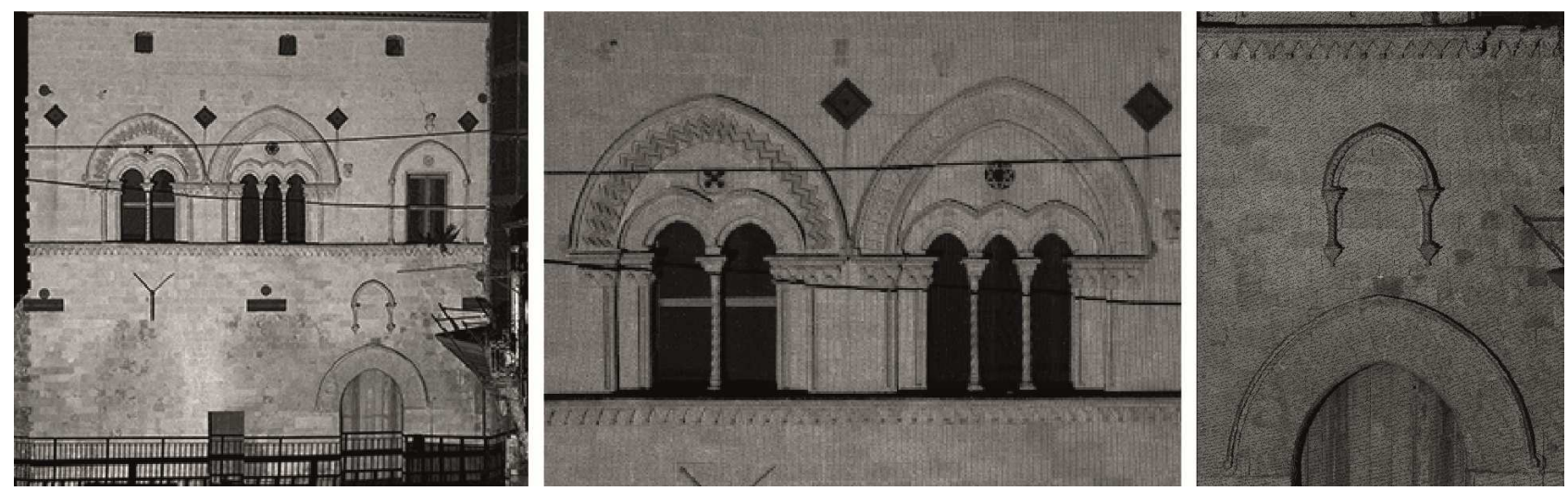

Figure 2. Complexity captured by all the point clouds referred to an architectural context of Ortigia.

For this reason, during the initial phase of research, a Qr code is associated to each significant urban and architectonic element, by which through the use of a suitable device such as a smart phone, permits the interactive reading of alphanumeric information that in turn becomes an online consultation guide to the virtual reality.

\section{AN IMPLEMENTABLE MODEL FOR A SUSTAINABLE GOVERNMENT $\quad(R$. Valenti $)$}

The methodological approach of this study tackles the issue of managing information that is highly interrelated, referring to the entire monumental unicum of Ortigia, by means of the recognition of the parts at times also fragmentary.

In order to achieve the objective of penetrating the context, the survey, in implementing a complex fact-finding process, must base its articulation on a system of investigation that can focus on the signs and languages making up the substrate of a collective memory that, unconsciously, recognizes in these the very identity of the place.

Furthermore, referring to the historical urban scenery of Ortigia, the representation, through the elaboration of a complex model, must communicate the aesthetic significance which the community attributes to this place and must capture the symbolic references, non-necessarily of building matter, that stem from the perception of a reasoned survey.

This method has refined an informational system capable of adding stimulus to the interacting process of the data collected, according to a strict level of high capacity interconnectivity communication. The model that has been elaborated presents itself as a conceptual system capable of simplifying the complexity of the interactions that are generated during the evolutionary analysis of the historical built environment.

Therefore, a fact-finding investigation was organised regarding the formal perception of the urban historical landscape of Ortigia that takes advantage of the relationship between instruments of communication and the new possibilities of visual structures, tied to the dynamics of the temporal and spatial development of the geographic - architectonic dimension, and which is capable of transferring and diffusing the complex information acquired according to objective and easily manageable systems. (Figure 3 )

During the cognitive approach, Ortigia has the particular potentiality to reveal itself by way of fragments through which it is possible to carry out a detailed interpretation that may provide an explanation of the original architectonic nuclei, of the transformations, consequences of political, social, economic, cultural and natural processes which the city has undergone.

The opportunely organized knowledge, according to ordered schemes, can attribute to the amount of information, ever more abundant, a narrative and evolutionary sequence, able to connect apparently isolated signs and which are essentially linked by the history that unites Ortigia with a broader territory to investigate.

According to this perspective, the detailed knowledge by way of fragments, of the monumental context of Ortigia, organized in synthesis according to thematic qualitative relationships, becomes a tool with which to reveal the signs of an obvious, though not easy intelligible stratification, finalized to a fair and shared management of the patrimony.

The interpretation, which is detailed and perceptively sensitive, of the stone archive signals not only the more evident or already known stratifications, but more importantly, the missing stratifications, which have been cancelled by the functional or aesthetic changing needs, the memory stratifications, or rather the symbolic signs in which reside the recollection of the layout of the land and the missing memory stratifications, which are no longer visible but whose recollection is attached to other signs which evoke its' existence.

The survey is further enriched: the information which is transferred into the informational system is not only tactile but also that which the memory guards its meaning and need for protection. The need that, if opportunely shared, establishes the true measure of widespread social use.

That is to say that it is most likely feasible if the information that arises from the method is explained and transmitted among all the different user levels.

The use of the Web and interactive multimedia tools allow for a democratic capacity of communication, which becomes decisive if it reaches individuals in charge of making decisions.

Hence, the involvement of the different branches of government is a fundamental condition so that every effort of research can be a substantial aid to the sustainable development based on the safeguard of the historical evidence and the signs which are introspectively guarded.

Without a doubt, raising awareness among those working in the various administrative sectors and stimulating the sharing of joint policies of intervention, aimed at tourist-cultural routes, may induce economic benefits in territories with strong cultural values. 


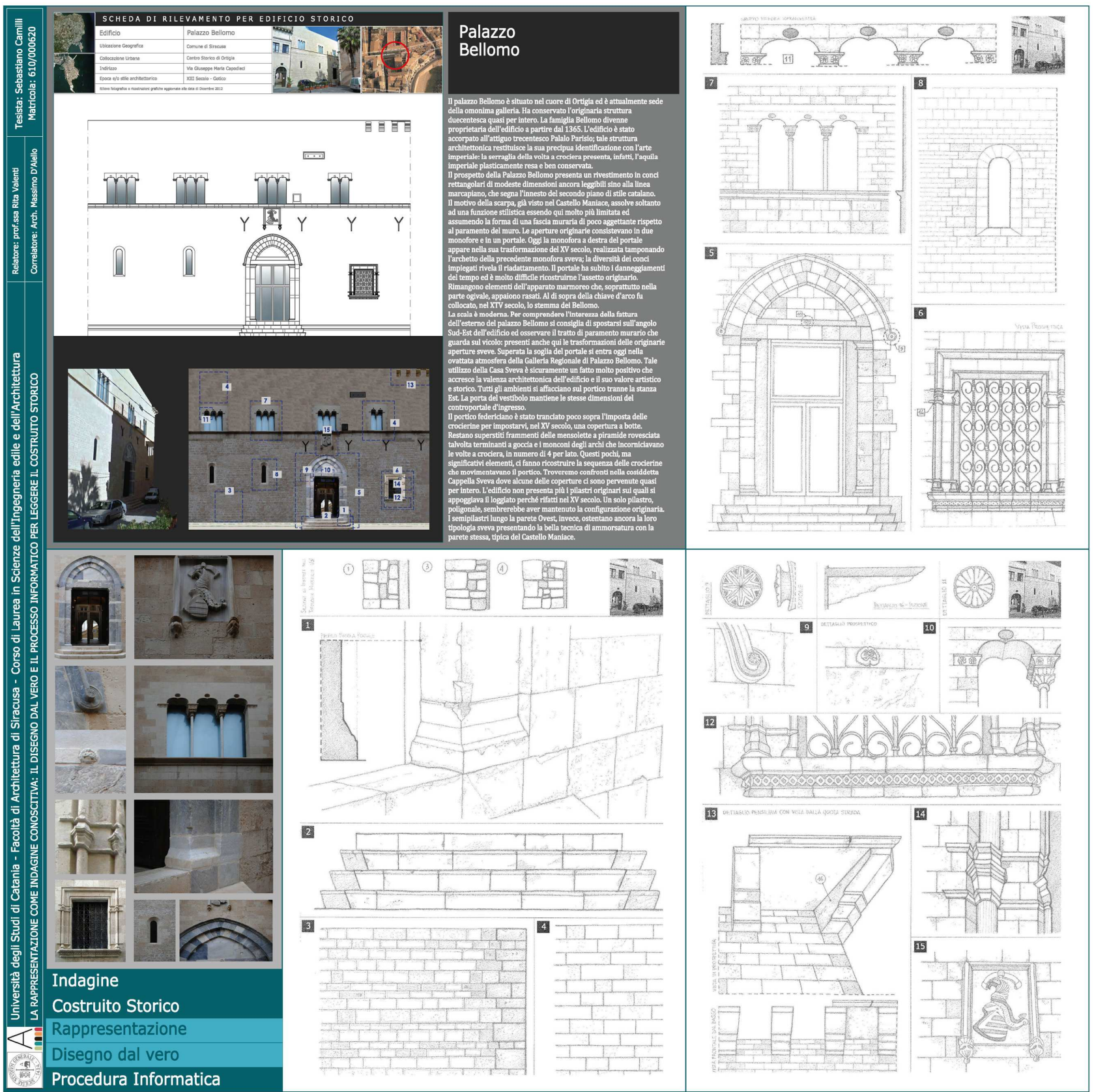

Figure 3. Representation as a cognitive investigation.

The drawing from real life and the informational technology process to read historical buildings.

(Degree Thesis of Sebastiano Camilli, supervisor: R. Valenti, co-examiner: M. D'Aiello)

\section{A CULTURAL-TECHNOLOGICAL PROCESS FOR KNOWLEDGE (M. Liuzzo}

To initiate, through precisely composite systems in the field of Representation, a cognitive procedure on the volumetric and material textures and on the architectonic quality of the historical built environment, is born from the will to create an investigative method that is an effective vehicle for information, useful to document reality and to capture, in real time, the attention and sensitivity of citizens, of tourists and of the authorities responsible for managing the transformations of the territory.
Considering this responsibility, a suite of digital instruments, online and offline, called Crabnebula, has been conceived and applied to a significant portion of Ortigia, with the aim of uniting useful information towards a critical interpretation of the places: from the integrated environmental survey, both urban and architectonic, to the three-dimensional rendered model.

A database, which accompanies the virtual model as a means of support and whose content and categories of information can always be updated, allows for the collection of much more information that when opportunely catalogued and dated, within 
its overlapping and relating, can allow for a global comprehension based on the discernment and recomposing of the parts. (Figure 4)

The architecture of the Crabnebula digital suite has been currently equipped with two interrelated software modules that are capable of respectively managing the input phase, the collecting and interrelating of various useful pieces of information for means of interpreting the investigated places, and the output stage, namely the widespread communication of such information.

The cultural assumption, that guided the methodological choices and the structuring of the suite, is to direct the process of knowledge toward an essential linking of the exploration and analyses phases of the real context, with knowledge as their ultimate goal, and of communication, to reach the vastest sharing of such knowledge, with the guarantee of an anticipatory sharing of criteria and norms of such communication.

This desire to render the knowledge of the spatiality of the investigated site communicable and at the same time both coherent and accurate, has been decisive in choosing a threedimensional representation of synthesis which allows for a controlled transposition, through mesh and nurbs, of the survey data, and therefore an accurate representation of any architectonic form, attributable to the assembly and transformation of a primitive three dimensional to the more complex solids and surfaces of free and organic forms.

The intrinsic potential of virtual reality, to express itself through mimetic representations of phenomenal realities that may be transmitted, without overlooking those aspects of precision and reliability demanded of coded graphic representations, signifies that the same medium can be conceived to aid in the sharing of information between various kinds of users, in order to favour new and beneficial relationships of cooperation between operators and users of the common patrimony.

On one hand, it was thought of to use encoded two-dimensional graphic representations to stand along side the threedimensional representation of synthesis, not as self-standing drawings, but as correlated data, above all in anticipation of the transformations of the real scenario to be transferred, coherently and in rapid time, into all the representations through an interface of dynamic data updating. (Figure 5)

On the other hand, believing a priority the chance to exploit today's current multimedia technologies in order to promote the daily use of a culturally oriented city, in an initial phase of research, the Crabnebula suite envisioned associating a $\mathrm{Qr}$ code, linked to the database, to every significant urban and architectonic element of the digital model of Ortigia, which - by means of suitable devices commonly used such as a smart phone or tablet, or even positioning fixed totems in important points of the urban historical fabric - allows for the interactive reading of alphanumeric information which in turn acts as an on-line guide with which to consult the virtual reality.

The research is currently on-going and further software developments are under way, specifically regarding the output module, which is oriented towards the more highly evolved potential of the "heightened reality", providing the possibility to connect information from Crabnebula's database to existing buildings, or to a graphic or photographic representation of these same buildings, utilizing GPS satellite positioning. In this way the visual perspective of the object, mediated by a digital instrument, can be virtually enhanced with greater graphic, photo-realistic, and alphanumeric information; creating a highimpact sensory-immersion experience.
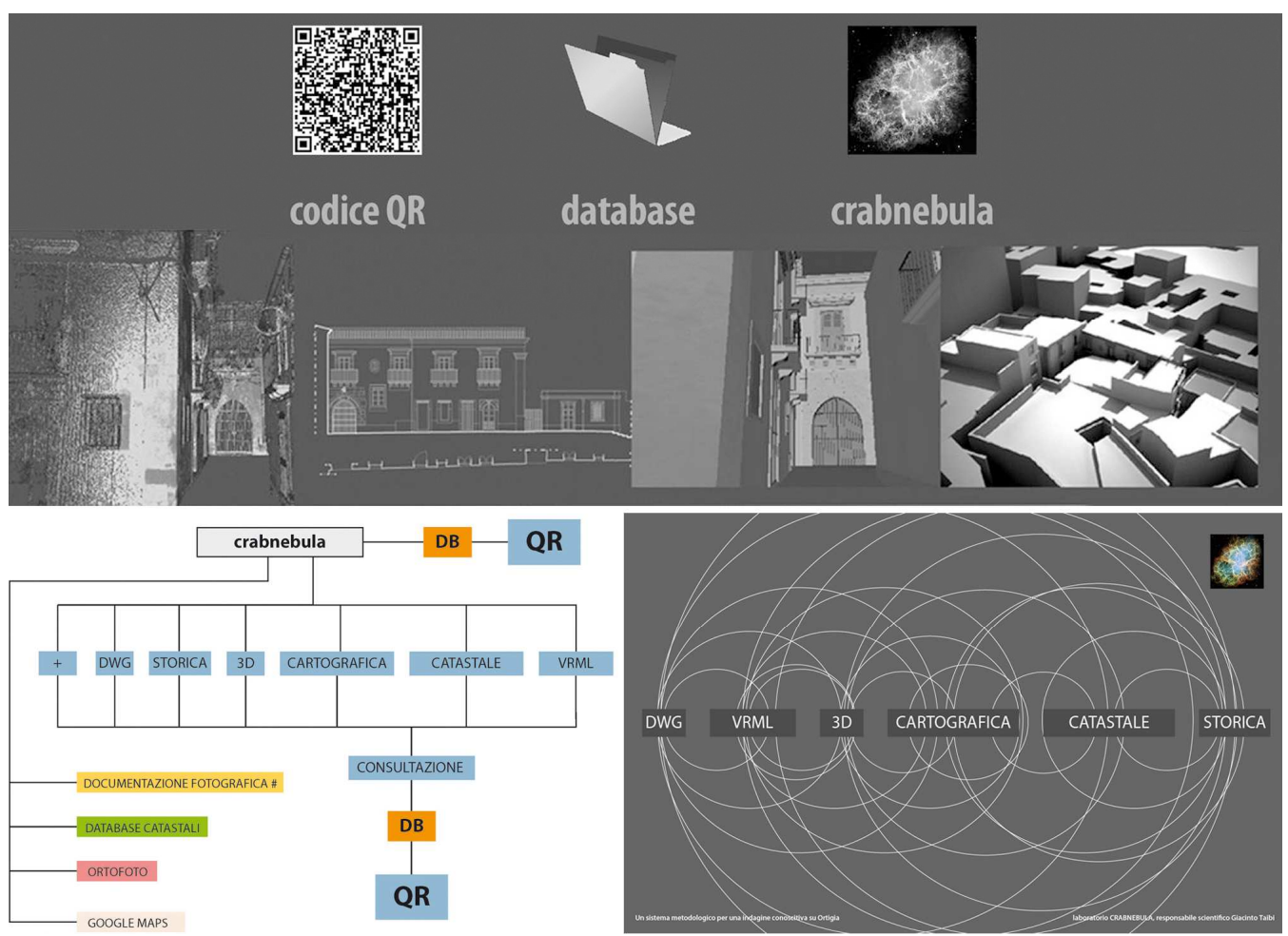

Figure 4. The process of knowledge based on exploring, analyzing, knowing, sharing and communicating. 


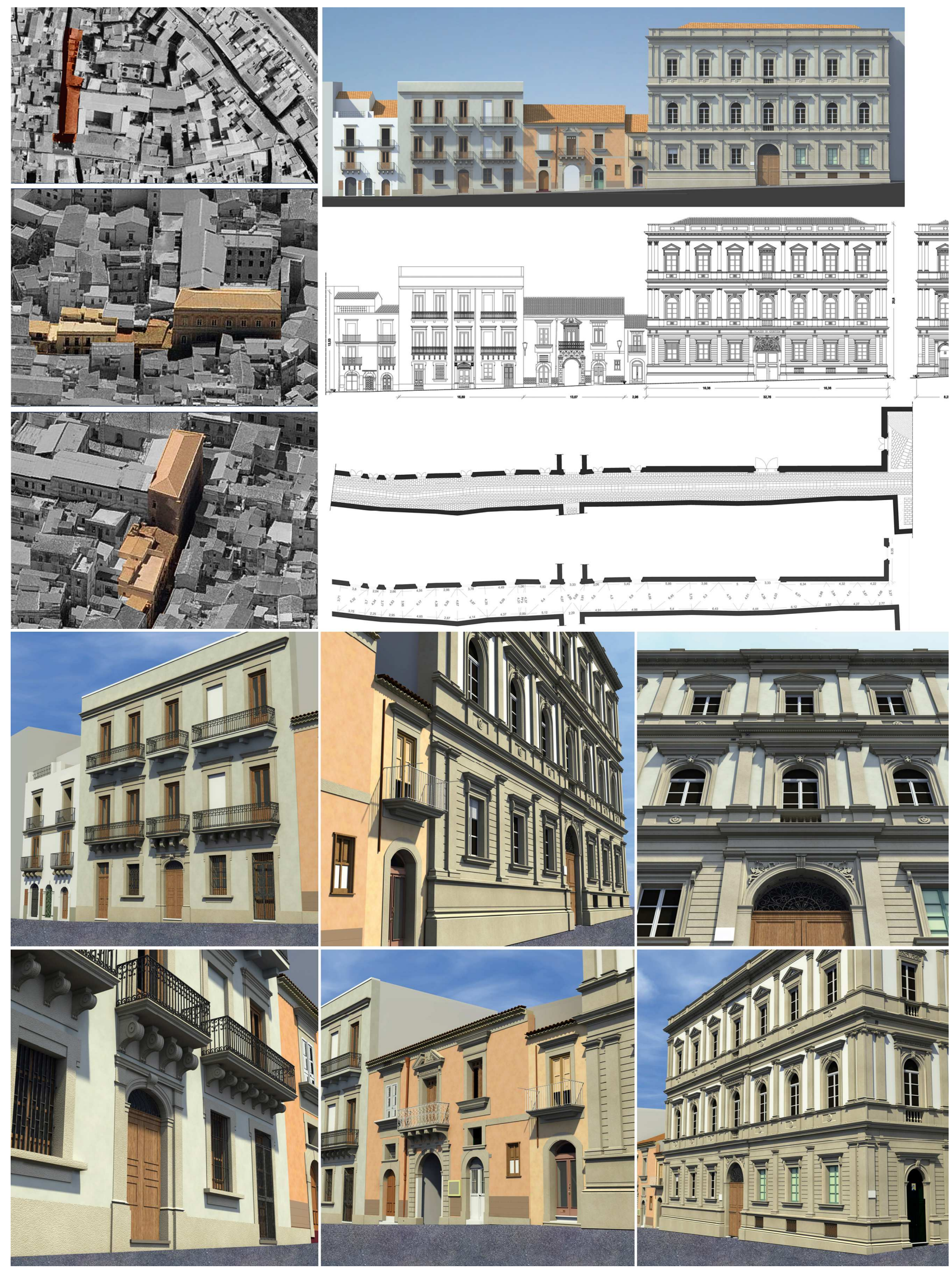

Figure 5. A logical and experimental system to define an integrated path of knowledge of the place. 


\section{CRABNEBULA SOFTWARE (M. D’Aiello)}

Crabnebula, a complex system devised within the frame of the Laboratory of Representation, came about from the need to manage a complex set of information (historical/architectonic and others), initially regarding the historical fabric of Ortigia and, successively, the management, maintenance and computerization of the cultural heritage, with the aspiration of becoming "the identity card of historical-cultural heritage".

It is a Web application, entirely developed in Java, whose software has been created as an open platform for modules that can be implemented following a horizontal growth process, with the aim of developing it quickly. (Figure 6)

Crabnebula is structured as two stand-alone applications.

The first application, more traditional, resides in a private network and allows research work in laboratory, while the second one is genuine web-app, comprising the consultation of data and the online publication system of the Crabnebula database.

In its first release, the system allows the management of the architectonic heritage, relying on a number of databases that operate together to filter the data.

Once the operation of deploying the application on a computer to act as server is performed by an administrator, all the terminals belonging to the same LAN network can access the functions, by typing the address of the application into the navigation bar of the browser.

The system is structured on different levels of access, ranging from the simple user, to the work team on a specific field of work.

Its main functions concern the insertion, consultation and successive modification of buildings and any other related data or information and they are displayed by means of a user interface, accessible by Web browser. Currently, the application is designed and optimized for use with Internet Explorer 8 and newer versions.

The system, already from its release, allows keeping together in addition to the classic information of the database and to the collection of data, like the registry cards of the architectonic heritage assets - files of different kinds, ranging from raster images to 3D models (3ds and c4d files). (Figure 7)

Through open source software modules, it enables, in a direct and immediate way, some operations without closing the program, thus as happens for the treatment of the images.

The access to the information in the first phase of testing is through the use of Qr codes, the system chosen for its implementability, diffusion, ease of use and without commercial licensing restrictions.

By using any tablet or smartphone, equipped with a Qr codes reader, one can obtain all the information held on the server in real time, filtered according to the level of access to the software.

At the moment, in the development and beta-testing phase, is a new visualization and data search system through the virtual rendering of the maps based on heightened reality, which will free the system from "Qr poles", a module to enable "team working" on a "cloud" platform, allowing a team to work on the same files in remote, as well as a dedicated application for the smartphone.

The choice to create a web application rather than a Smart client has enabled devising a readily accessible product on a distributed network, limiting installation and compatibility problems with other software on the users' computers.

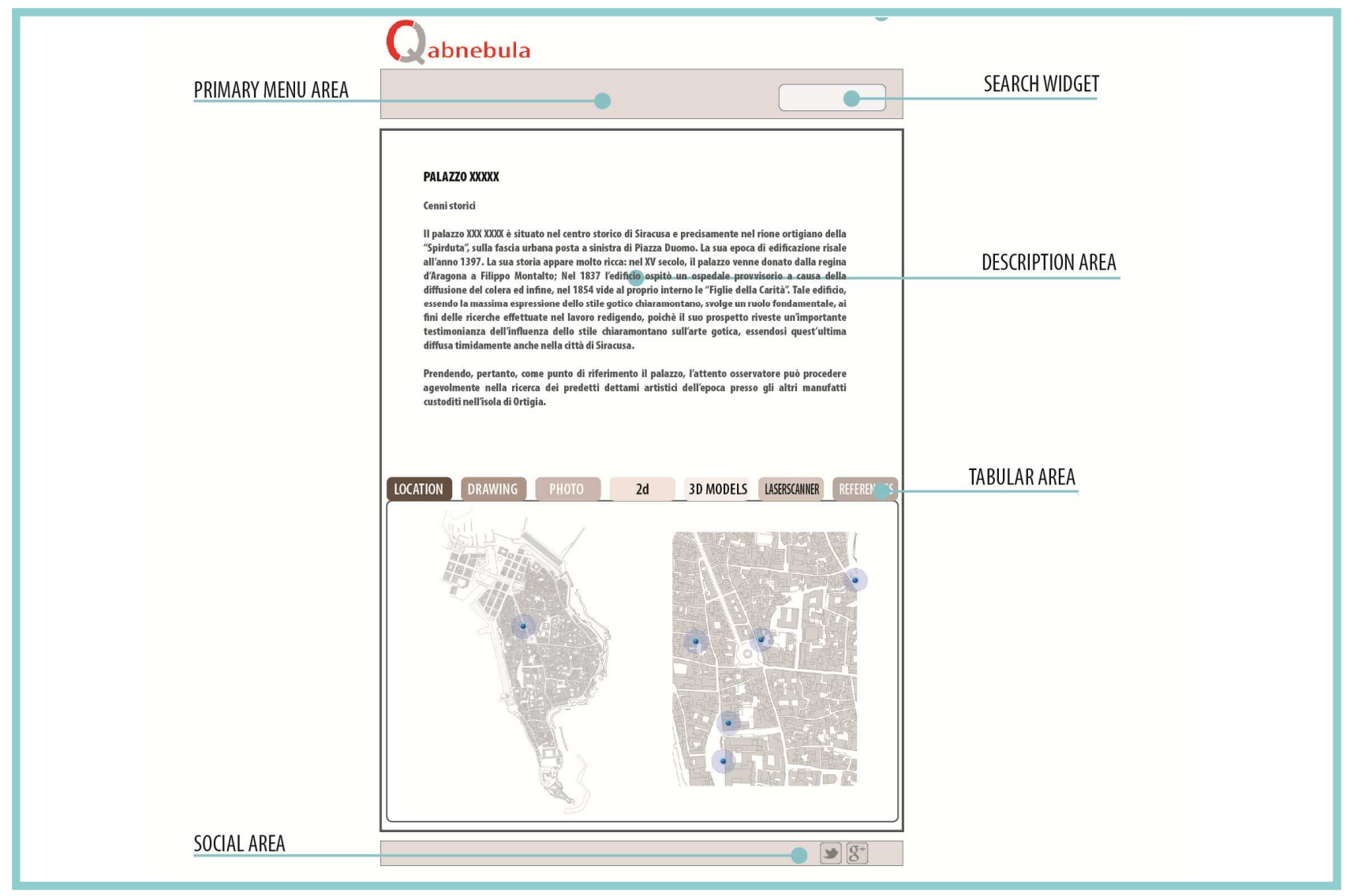

Figure 6. Crabnebula software. Layout. 


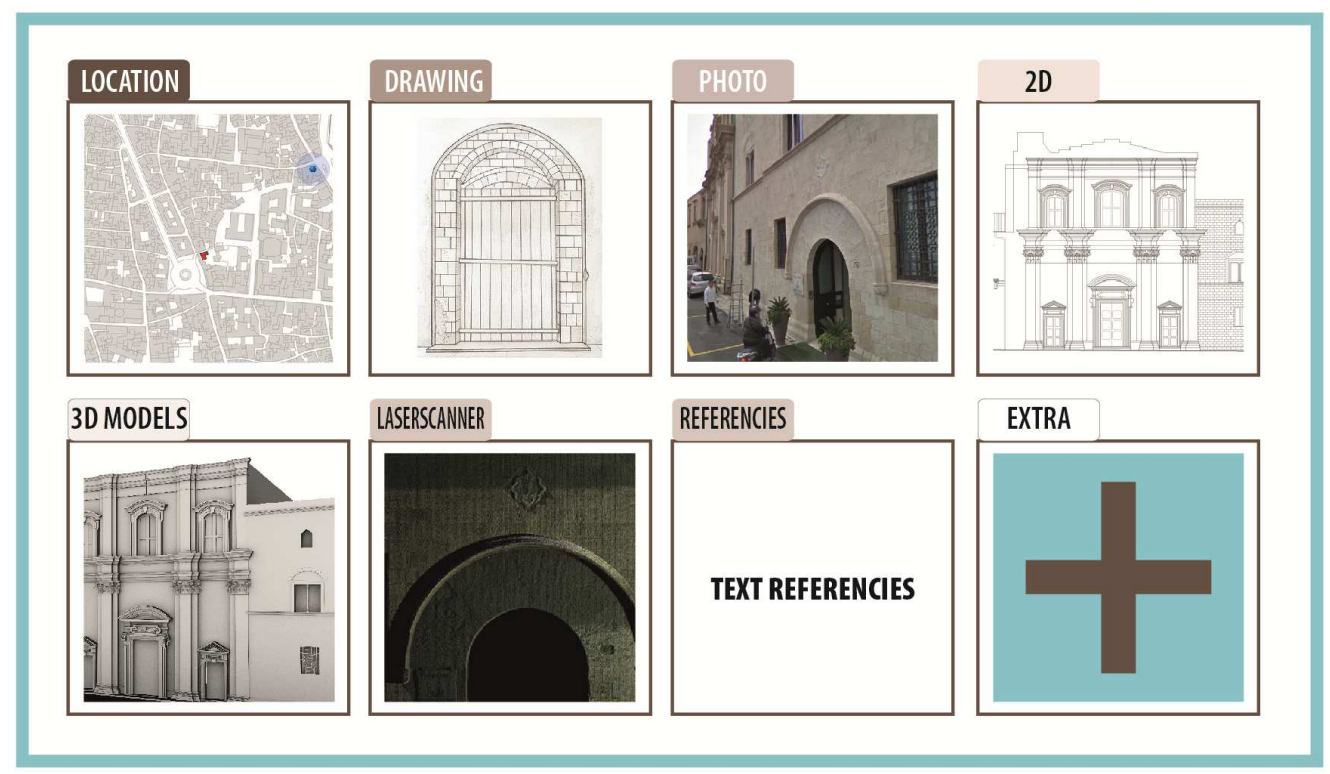

Figure 7. Crabnebula software. Elements of the information technology frame.

\section{CONCLUSIONS (G. Taibi)}

In light of the legacy of research previously carried out and of the already acquired experience, it is legitimate to hope for the creation of an outline document, namely a Charter of the Quality of the Survey, understood as a system of quality aimed at raising awareness towards protecting the territory, that can gather the results of all the experiments carried out in the field in the various research centres.

This entails conceiving of a Handbook of maintenance and safeguarding of the landscape, an instrument of intervention suited to resolving the structural and constituent elements determining the landscape aspects, which investigates the history and nature of the places and analyzes their evolution, stratification, settlement structure and the environmental andlandscape configuration. With great enthusiasm we are increasingly heading toward a survey document that is universally certifiable and that has recognizable criteria so that a survey certification can be issued.

\section{REFERENCES}

AA.VV., 2012. Trame e stratificazioni urbane. Casi studio a confronto. Atti della giornata di studio IL DISEGNO DI ORTIGIA. Frammenti a confronto, Siracusa 28 settembre 2012, Siracusa: Lettera Ventidue, 2012, 201 pp. ISBN 978-88-624272-3

Baculo Giusti Adriana, 2001. Dal rilievo al recupero architettonico urbano e ambientale. In Quaderno D.A.U. n.20. Roma: Gangemi, 2001, pp. 45-50. ISBN 88-492-0316-0

Centofanti Mario, Brusaporci Stefano, 2005. Il rilievo della città storica tra disegno dell'architettura e rappresentazione cartografica. In Volta Valentino (edited by). Immagine della città europea. Legnago: Tamellini, 2005, p. 183

Centofanti Mario, Brusaporci Stefano, 2011. L'Aquila "invisible city": surveying preservation and restoration of the city. In Gambardella Massimo (edited by). Le Vie dei Mercanti.
S.A.V.E. HERITAGE Safeguard of Architectural, Visual, Environmental Heritage. Napoli: La Scuola di Pitagora, 2011, pp. 1-10. ISBN: 978-88-6542-046-1

Coppo Dino, Boido Cristina (edited by), 2010. Rilievo urbano. Conoscenza e rappresentazione della città consolidata. Firenze: Alinea, 2010, 207 pp. ISBN: 97-88-6055-536-6

D’Aiello Massimo, 2011. Un sistema metodologico per una indagine conoscitiva su Ortigia, Degree Thesis, supervisor Giacinto Taibi, co-examiner Mariangela Liuzzo. Università di Catania, Facoltà di Architettura, Siracusa: a.a 2010-2011

De Rubertis Roberto, 1994. Il disegno dell'architettura. Roma: NIS, 1994, 260 pp.

Fusco Girard Luigi, 1989. Qualità e quantità nello sviluppo urbano. I riflessi sui problemi della valutazione. In Nijkamp Peter, Voogd Henk. Conservazione e sviluppo: la valutazione nella pianificazione fisica. Milano: Franco Angeli, 1989. ISBN 88-204-3573-X

Giandebiaggi Paolo, Vernizzi Chiara, 2010. Rilevare le città. Rappresentare la conoscenza con i sistemi informativi. In Gambardella Massimo (edited by). Le Vie dei Mercanti. Rappresentare la conoscenza. Napoli: La Scuola di Pitagora, 2010. ISBN 978-88-6542-014-0

Liuzzo Mariangela, 2011. La virtualità per una implementazione della conoscenza. In $\mathrm{Il}$ disegno delle trasformazioni. Napoli: CLEAN, 2011. ISBN 88-8497-215-6

Settis Salvatore, 2012. Paesaggio Costituzione Cemento. La battaglia per l'ambiente contro il degrado civile. Torino: Einaudi, 2012. ISBN: 978-88-0619-871-8

Taibi Giacinto, Valenti Rita, 2011. La modellazione come strumento di controllo e di salvaguardia del patrimonio storico. In Gambardella Massimo (edited by). Le Vie dei Mercanti. S.A.V.E. HERITAGE Safeguard of Architectural, Visual, Environmental Heritage. Napoli: La Scuola di Pitagora, 2011, pp. 1-10. ISBN: 978-88-6542-046-1

Crabnebula software: http://www.crab-nebula.com 